\title{
OSTEOSSARCOMA EM CÃES
}

Tales Dias Prado ${ }^{1}$, Rejane Guerra Ribeiro ${ }^{2}$, Lara Ataídes Arantes Terçariol ${ }^{3}$, Anaíza Simão Zucatto do Amaral $^{4}$, Virgínia Gouveia da Silva Guimarães ${ }^{5}$

${ }^{1}$ Universidade Estadual Paulista, Faculdade de Ciências Agrárias e Veterinárias, Jaboticabal, SP

${ }^{2}$ Universidade Estadual Paulista, Faculdade de Ciências Agrárias e Veterinárias, Jaboticabal, SP

${ }^{3}$ Universidade de Rio Verde, Rio Verde - GO

${ }^{4}$ Universidade de Rio Verde, Rio Verde - GO

${ }^{5}$ Médica Veterinária autônoma, Rio Verde - GO

Autor correspondente: talesprado@yahoo.com.br

Recebido em: 05/12/2014 - Aprovado em: 14/12/2014 - Publicado em: 15/12/2014

\section{RESUMO}

O osteossarcoma ou sarcoma osteogênico é um tumor ósseo maligno que representa cerca de $80 \%$ a $95 \%$ dos tumores ósseos primários. Ocorre com maior frequência no esqueleto apendicular. Possui crescimento rápido, invasivo e alto potencial metastático. Esta doença é mais observada em animais de raças grandes e gigantes, machos, de meia idade a idosos. Existem diversos meios para diagnóstico, dentre eles incluem o histórico clínico, exame físico, achados radiológicos, tomografia computadorizada, cintilografia e ressonância magnética, sendo necessário, a biópsia e o exame histopatológico para confirmação do tipo de neoplasia. A principal forma terapêutica atualmente utilizada é a amputação do membro acometido associada à quimioterapia. $O$ prognóstico permanece de reservado à desfavorável.

PALAVRAS-CHAVE: Canino, metástase, sarcoma, tumor.

\section{OSTEOSARCOMA IN DOGS}

Osteosarcoma or osteogenic sarcoma is a malignant bone tumor that represents about $80 \%$ to $95 \%$ of primary bone tumors. It occurs most frequently in the appendicular skeleton. It has fast, invasive and metastatic potential high growth. This disease is most commonly observed in animals of large and giant breeds, male, middle-aged to elderly. There are several ways to diagnosis, among them the clinical history, physical examination, radiographic findings, computed tomography, scintigraphy and magnetic resonance imaging. Biopsy and histopathological examination may be done to confirm the type of cancer. The main form of therapy currently used is the amputation of the affected limb associated with chemotherapy. The prognosis remains reserved to unfavorable.

KEYWORDS: Canine, metastasis, sarcoma, tumor.

\section{INTRODUÇÃO}

O osteossarcoma ou sarcoma osteogênico representa cerca de $80 \%$ a $95 \%$ dos tumores ósseos primários em cães, sendo o principal tumor ósseo maligno em humanos (PIMENTA et al., 2013). O osteossarcoma (OSA) é observado com maior 
frequência em raças gigantes ou de grande porte. Os machos têm maior possibilidade de apresentar a neoplasia, entretanto osteossarcomas de esqueleto axial acometem mais as fêmeas (DALECK et al., 2006). Raramente ocorrem em ossos do esqueleto axial como crânio, costelas, vértebras e pelve (MARTELLI et al., 2007).

O OSA é um tumor localmente invasivo e altamente metastático, apresentando predileção pelo pulmão (90\%). Nos 10\% restantes, as metástases ocorrem em outros órgãos ou ossos (SILVEIRA et al., 2008).O diagnóstico é fundamentado na anamnese, exame físico, achados radiológicos, cintilografia óssea e tomografia computadorizada sendo a confirmação realizada através de biópsia e exame histopatológico (DALECK et al., 2006).

A intervenção cirúrgica, associada à quimioterapia, consiste na terapêutica que possibilita maior sobrevida, sendo indicada com maior frequência para 0 tratamento de osteossarcoma apendicular (OLIVEIRA \& SILVEIRA, 2008a; SILVEIRA et al., 2008) Esta revisão tem como objetivo realizar uma descrição da abordagem clínica do osteossarcoma através das características histológicas, localização, tratamento, métodos de diagnóstico, formação das lesões metastáticas, prognóstico e sobrevida do paciente.

\section{REVISÃO DE LITERATURA}

\section{Características gerais das neoplasias ósseas}

As neoplasias são classificadas de acordo com as características de comportamento e crescimento sendo divididas em benignas, são tumores que crescem por expansão além da invasão, não provocam metástases e geralmente não são fatais, ou malignas, são tumores caracterizados por sua forma invasiva e destrutiva, tendo possibilidade de metástases por via linfática, para linfonodos locais e regionais ou por via hematógena, permitindo o desenvolvimento de tumores secundários em qualquer órgão do corpo, podendo levar à morte, a não ser que um tratamento seja iniciado imediatamente (MORRIS \& DOBSON, 2007).

Os tumores ósseos primários ocorrem em cerca de 3 a $4 \%$ de todos os tumores malignos em cães, sendo também descritos em gatos e humanos. Os cães de raças de grande porte e animais de meia idade a idosos apresentam maior predisposição de desenvolver essa enfermidade, podendo ocorrer também em animais jovens, já os tumores benignos são raros (ANDRADE, 2008).

Neoplasias ósseas primárias surgem de células que ficam localizadas dentro da estrutura óssea. Os tumores de tecido mole podem disseminar para o tecido ósseo nos esqueletos apendicular (ossos longos) ou axial (crânio, vértebras, costelas e pelve) (JOHNSON \& HULSE, 2005).

As neoplasias ósseas primárias são muito comuns em cães e raramente ocorrem em gatos. A grande maioria dos tumores ósseos nos cães é maligna, pois geralmente causam a morte do animal como resultado da infiltração local (fraturas patológicas ou dor intensa levando à eutanásia) ou metástases. Embora raro a maioria das neoplasias ósseas primárias em gatos, histologicamente malignas, são curadas por excisão cirúrgica ampla (COUTO, 2006).

Em cães e gatos, os tumores ósseos primários superam muito os tumores ósseos secundários, embora não existam dados precisos sobre a prevalência de cada tipo de tumor (WATERS, 1998). Os tumores ósseos que ocorrem com maior frequência nos cães são os osteossarcomas, condrossarcomas, osteocondromas, hemangiossarcomas, fibromas e lipossarcomas (Quadro 1). De todas as neoplasias 
ósseas, o osteossarcoma é o mais frequentemente relatado na espécie canina (CANOLA \& MEDEIROS, 2008).

QUADRO 1 - Neoplasias ósseas malignas em cães

\begin{tabular}{|c|c|c|c|c|}
\hline TUMOR & INCIDÊNCIA & METÁSTASE & TRATAMENTO & PROGNÓSTICO \\
\hline $\begin{array}{l}\text { Osteossarcoma } \\
\text { do esqueleto } \\
\text { apendicular }\end{array}$ & $75 \%$ & $\begin{array}{l}\text { Pulmões e } \\
\text { tecidos } \\
\text { moles são } \\
\text { rapidamente } \\
\text { afetados; } \\
\text { Metástase } \\
\text { óssea é uma } \\
\text { complicação } \\
\text { tardia; }\end{array}$ & $\begin{array}{l}\text { Amputação; } \\
\text { Quimioterapia } \\
\text {; } \\
\text { Salvamento } \\
\text { de membro; } \\
\text { Radioterapia; }\end{array}$ & $\begin{array}{l}\text { Somente } \\
\text { amputação: } 12 \text { a } \\
16 \text { semanas; } \\
\text { Amputação ou } \\
\text { salvamento de } \\
\text { membro mais } \\
\text { quimioterapia: } \\
300 \text { a } 400 \text { dias; }\end{array}$ \\
\hline $\begin{array}{l}\text { Osteossarcoma } \\
\text { do esqueleto } \\
\text { axial }\end{array}$ & $\begin{array}{l}\text { Menos } \\
\text { comum que } \\
\text { os } \\
\text { apendicular } \\
\text { es }\end{array}$ & $\begin{array}{l}\text { Altamente } \\
\text { metastático; } \\
\text { Recorrência } \\
\text { local; }\end{array}$ & $\begin{array}{l}\text { Ressecção } \\
\text { local; } \\
\text { Quimioterapia } \\
\text { Radioterapia; }\end{array}$ & $\begin{array}{l}\text { Sobrevivência } \\
\text { média: } 22 \\
\text { semanas; }\end{array}$ \\
\hline Condrossarcoma & $5-10 \%$ & $\begin{array}{l}\text { Mais lento } \\
\text { que o } \\
\text { osteossarco } \\
\text { ma; }\end{array}$ & Amputação; & Favorável; \\
\hline Fibrossarcoma & $0-5 \%$ & Lento; & $\begin{array}{l}\text { Amputação; } \\
\text { Salvamento } \\
\text { de membro; }\end{array}$ & Desfavorável; \\
\hline $\begin{array}{l}\text { Hemangiossarco } \\
\text { ma }\end{array}$ & $3-5 \%$ & $\begin{array}{l}\text { Altamente } \\
\text { metastático; } \\
\text { Pode ser } \\
\text { multicêntrico; }\end{array}$ & $\begin{array}{l}\text { Amputação; } \\
\text { Salvamento } \\
\text { de membro; }\end{array}$ & Desfavorável; \\
\hline $\begin{array}{l}\text { Tumor de células } \\
\text { gigantes }\end{array}$ & Rara & $\begin{array}{l}\text { Metástase } \\
\text { em } \\
\text { linfonodos, } \\
\text { pulmão e } \\
\text { ossos; }\end{array}$ & Amputação; & Desfavorável; \\
\hline Lipossarcoma & Rara & $\begin{array}{l}\text { Metástase } \\
\text { em pulmão, } \\
\text { fígado e } \\
\text { linfonodos; }\end{array}$ & $\begin{array}{l}\text { Amputação; } \\
\text { Ressecção } \\
\text { local; }\end{array}$ & Desfavorável; \\
\hline $\begin{array}{l}\text { Sarcoma } \\
\text { associado com } \\
\text { fratura }\end{array}$ & $\begin{array}{l}\text { Representa } \\
5 \% \text { dos } \\
\text { osteossarc } \\
\text { omas }\end{array}$ & $\begin{array}{l}\text { Ocorreu } \\
\text { metástase } \\
\text { em } 14 \% \text { dos } \\
\text { casos } \\
\text { descritos }\end{array}$ & $\begin{array}{l}\text { Amputação; } \\
\text { Salvamento } \\
\text { de membro; } \\
\text { Quimioterapia }\end{array}$ & $\begin{array}{l}\text { Mesmo que o } \\
\text { osteossarcoma; }\end{array}$ \\
\hline
\end{tabular}

Fonte: Adaptação de JOHNSON \& HULSE (2005). 


\section{Osteossarcoma}

O osteossarcoma (OSA) ou sarcoma osteogênico representa cerca de $80 \%$ a $95 \%$ dos tumores ósseos primários em cães. Em humanos é o principal tumor ósseo maligno (PIMENTA et al., 2013). Este tumor é mais comum de ocorrer no esqueleto apendicular, que no axial. O OSA apendicular possui predileção por regiões "próximos ao joelho, longe do cotovelo", e a porção distal do rádio é o local primário mais comum. Quase todos os tumores são metafisários, embora possa ocorrer osteossarcoma diafisário (WATERS, 1998). Os membros torácicos são mais acometidos que os pélvicos (SILVEIRA et al., 2008).

A etiologia do OSA ainda permanece desconhecida. Especula-se que esta neoplasia poderia ter uma origem viral, pois pode ocorrer em ninhadas e, também, pode ser induzida experimentalmente pela injeção de células neoplásicas em fetos de cães. Entretanto, ainda não foi isolado nenhum vírus responsável pelo surgimento do osteossarcoma canino (DALECK et al., 2008).

Existem teorias que se baseiam na evidência, de que o OSA tende a ocorrer nos ossos que sustentam os maiores pesos e em sítios adjacentes às fises de fechamento tardio, e por esse motivo que os animais de grande porte são predispostos a pequenos e múltiplos traumas nas regiões metafisárias, onde possui maior atividade celular. A sensibilização de células nesta região pode provocar início da doença pela indução de sinais mitogênicos, elevando a probabilidade de desenvolvimento de uma linhagem mutante. Existem relatos de OSA em regiões de fraturas associada a implantes metálicos e que são acometidos por osteomielite crônica e, também, em fraturas em que não se utilizou nenhuma forma de fixação interna (DALECK et al., 2002; ALCÂNTARA et al., 2010).

$A$ radiação, tanto experimental quanto terapêutica, tem sido descrita como uma causa de OSA canino. Em um estudo, foi relatado o desenvolvimento de OSA em 3 dos 87 cães submetidos à terapia de radiação como tratamento para sarcomas de tecidos moles após um ano e sete meses a cinco anos (DALECK et al., 2008). A maioria dos OSA se origina no canal medular de ossos longos, principalmente, na metáfise, mas alguns se originam na superfície cortical, periósteo e em sítios extraesqueléticos (DALECK et al., 2008).

A forma esquelética é mais comum de ser acometida, podendo ocorrer tanto no esqueleto axial quanto no apendicular. A forma extra-esquelética envolve os tecidos moles e é um tipo raro em cães, correspondendo a $1 \%$ dos casos (ANDRADE, 2009; PAZZINI \& DALECK, 2013). O OSA se desenvolve principalmente em ossos longos (75\%), sendo denominado de osteossarcoma apendicular e os $25 \%$ restantes se desenvolvem no crânio e esqueleto axial (DALECK et al., 2008; OLIVEIRA \& SILVEIRA, 2008b).

O osteossarcoma extra-esquelético geralmente acomete cães idosos, não possui predisposição por sexo e as raças mais acometidas são Rottweiller e Beagle (ANDRADE, 2009). Os locais com maior ocorrência desse tumor nos cães, em um estudo de 169 casos foram as glândulas mamárias, sistema digestório, tecido subcutâneo, fígado e baço, havendo casos descritos em glândulas salivares e tireóide, pulmão, rins, bexiga, olhos e mesentério (ARAÚJO et al., 2006).

Os OSA geralmente acometem cães de meia idade (7,5 anos) e idosos, também pode acometer animais jovens. O OSA apendicular é observado com maior frequência em raças grandes e gigantes. As raças mais predispostas a desenvolver essa neoplasia são o São Bernardo, Dinamarquês, Setter Irlandês, Dobermann, 
Pastor Alemão, Rottweiler, Golden Retriever, Boxer, Fila Brasileiro e Mastiff (DALECK et al., 2008; OLIVEIRA \& SILVEIRA, 2008b).

O OSA apendicular pode acometer tanto os cães machos quanto as fêmeas, sendo maior a incidência dessa neoplasia em machos (SILVEIRA et al., 2008), com exceção das raças São Bernardo, Rottweiler e Dinamarquês, pois nessas raças se observa maior incidência nas fêmeas (DALECK et al., 2008; ANDRADE, 2009) .

Segundo DALECK et al. (2006), cães machos apresentam uma vez e meia maior incidência desta neoplasia do que as fêmeas, entretanto, quando os casos são de osteossarcoma do esqueleto axial, as fêmeas são mais acometidas que os machos. Na espécie humana, o OSA pode ocorrer em qualquer faixa etária, sendo que $75 \%$ desse tumor acometem pacientes com idade inferior a 20 anos, o segundo e menor pico ocorre nos idosos (MARTELLI et al., 2007).

O OSA canino apresenta semelhanças com o osteossarcoma em humanos, e devido a esse fato, o cão tem servido como modelo para o estudo comparativo da neoplasia. Entre as semelhanças do cão e o homem incluem a predileção pelo sexo masculino, pacientes grandes, o esqueleto apendicular é o mais acometido (75\%) com localização metafisária, etiologia desconhecida, as metástases geralmente ocorrem no pulmão, os tipos menos comum de OSA são similares entre as espécies. Nos humanos assim como nos cães a terapia padrão é a amputação associada com a quimioterapia (ANDRADE, 2008).

\section{Sinais clínicos}

Cães com neoplasias ósseas, especialmente o OSA apendicular, manifestam sinais clínicos de dor, claudicação aguda ou crônica com o membro apoiado em pinça e edema na área afetada. A dor é devido à microfraturas ou à interrupção do periósteo provocada pela osteólise do osso cortical, pela extensão tumoral do canal medular (DALECK et al., 2002). Podendo, ainda, apresentar tumefação da extremidade distal do rádio e da ulna, extremidade proximal do fêmur, da tíbia e do

úmero. Observam-se com frequência fraturas espontâneas durante 0 desenvolvimento da doença (DALECK et al., 2008).

O membro pode ter seu tamanho aumentado e estar com a consistência firme na área afetada, e raramente encontram-se fístulas cutâneas presentes. Pode-se ter histórico de diminuição progressiva no apoio do membro e atrofia muscular (JOHNSON \& HULSE, 2005).

Os sinais clínicos sistêmicos de enfermidade como febre, anorexia e perda de peso são incomuns na fase aguda da doença (PAZZINI \& DALECK, 2013). Podem ser observadas anormalidades respiratórias associadas com metástases em alguns animais (JOHNSON \& HULSE, 2005).

O exame físico geralmente revela aumento de volume doloroso na região afetada, com ou sem envolvimento do tecido mole. A dor e o edema podem ser de início súbito, levando ao diagnóstico de problemas ortopédicos não neoplásicos e, podendo levar a um considerável atraso no diagnóstico e no estabelecimento definitivo da terapia para a neoplasia (COUTO, 2006).

A principal manifestação clínica de sarcomas ósseos em humanos é a dor, que apresenta caráter progressivo e em poucas semanas torna-se de grande intensidade, não sendo responsiva a analgésicos comuns, o que se assemelha ao quadro clínico apresentado pelos cães (SANTOS, 2009).

O reconhecimento clínico dessa neoplasia localizada no esqueleto axial é mais difícil que do esqueleto apendicular, pois os sinais clínicos se manifestam mais 
tardiamente. Os sinais variam podendo ter desde edema localizado a disfagia, exoftalmia, dor ao abrir a boca, deformidade facial, corrimentos nasais, espirros e hiperestesia, com ou sem sinais neurológicos. Quando o OSA envolve a coluna vertebral, geralmente provoca debilidade neurológica associada à compressão da medula espinhal. Fraturas patológicas das vértebras podem levar ao avanço súbito dos sinais de mielopatia (DALECK et al., 2008).

Raramente são observados sinais respiratórios como a primeira evidência clínica de metástase pulmonar. Cães diagnosticados radiograficamente com metástases podem permanecer assintomáticos por muitos meses, contudo, alguns se tornam apáticos e anoréxicos dentro de um mês, podendo apresentar tosse, dispnéia, perda de peso e fraqueza (OLIVEIRA \& SILVEIRA, 2008a).

\section{Diagnóstico}

O diagnóstico tem como base o histórico clínico, o exame físico, o exame radiográfico, a tomografia computadorizada, a cintilografia e a ressonância magnética (DALECK et al., 2008). Embora o diagnóstico de OSA seja sugerido somente por achado radiográfico, a citologia e a histopatologia são necessárias para confirmação do diagnóstico (DALECK et al., 2008; OLIVEIRA \& SILVEIRA, 2008a; PAZZINI \& DALECK, 2013).

Deve ser destacada a importância de um amplo exame clínico e radiográfico, assim como da biópsia excisional, para se obter um diagnóstico conclusivo, diferenciando tumores ósseos primários malignos, tumores ósseos benignos, metástase tumoral e, principalmente, casos de osteomielite fúngica e osteopatia hipertrófica, pela semelhança das alterações radiográficas ósseas e periostais encontradas no OSA (OLIVEIRA \& SILVEIRA, 2008a).

A presença de metástase, identificada no momento do diagnóstico do ostessarcoma, é reconhecida como um fator de prognóstico desfavorável, sendo o tratamento menos eficaz em aumentar o tempo de sobrevivência nestes casos (OLIVEIRA \& SILVEIRA, 2008a).

\section{Exame radiográfico}

O exame radiográfico é o método mais utilizado para o diagnóstico de OSA, entretanto é considerado apenas diagnóstico sugestivo (DALECK et al., 2008). As radiografias são utilizadas na avaliação da extensão do envolvimento ósseo e para diferenciação entre neoplasias ósseas e outras alterações não neoplásicas, como fraturas, osteomielites e afecções ósseas metabólicas (WATERS, 1998; DALECK et al., 2008). Devido a muitos distúrbios ósseos terem aspectos radiográficos semelhantes, recomenda-se fazer um método lógico de avaliação para verificar se a lesão é agressiva ou não agressiva.

Recomendam-se parâmetros de avaliação de agressividade, como localização das lesões, taxa de mudança na aparência óssea, modelo de destruição óssea, envolvimento das corticais, características das margens de definição entre o osso normal e o osso anormal e neoformação. Esses parâmetros podem ser determinados através de radiografias seriadas (CANOLA \& MEDEIROS, 2008).

Alterações radiográficas como destruição cortical e a formação de novo osso periosteal podem levar ao diagnóstico de neoplasia óssea, mas raramente são patagnomônicas para um tipo de tumor (WATERS, 1998). Radiograficamente, os osteossarcomas caracterizam-se por osteólise, neoformação óssea irregular e 
ocasionalmente, edema de tecido mole com ou sem calcificação no local acometido da metáfise do osso. O Triângulo de Codman também pode ser observado assim como, destruição do córtex na área acometida e proliferação no periósteo (COUTO, 2006).

Quando ocorre destruição óssea, a lise óssea demonstra no exame radiográfico a diminuição na opacidade óssea. De 30 a $50 \%$ do osso por unidade de área deve estar destruído para que a lise seja visualizada na radiografia. Quando a cortical do osso é afetada, uma lesão óssea agressiva provoca lise parcial ou completa do córtex, aumentando a possibilidade de ocorrer fratura patológica, além de estender e envolver os tecidos moles (CANOLA \& MEDEIROS, 2008).

Sendo os pulmões o principal local de metástases do OSA, devem ser realizadas radiografias torácicas antes do tratamento com a finalidade de detectar doença metastática. As radiografias torácicas devem ser feitas no momento da inspiração e devem incluir três posições: ventrodorsal ou dorsoventral e lateral esquerda e direita. Os nódulos metastáticos de OSA são constituídos de tecido denso e só são visualizados quando apresentam diâmetro maior que 6 a $8 \mathrm{~mm}$ (DALECK et al., 2002). As radiografias torácicas raramente demostram a presença de metástases pulmonares no momento da consulta (SILVEIRA et al., 2008).

Segundo WATERS (1998), o triângulo de "Codman" não é patognomônico para osteossarcoma, podendo ser visualizado tanto em processos neoplásicos como em não neoplásicos. As reações periosteais estão presentes em média de $95 \%$ das lesões, apresentando aspecto de "explosão solar" (DALECK et al., 2008; OLIVEIRA \& SILVEIRA, 2008a; ANDRADE, 2009).

Observam-se lesões osteolíticas nos ossos longos caracterizadas por apresentarem bordas irregulares ou onduladas, com aspecto de "comido por traça" ou contorno ósseo alargado ao longo da parte trabecular da epífise. Essas lesões se estendem até a metáfise ou diáfise (DALECK et al., 2008).

\section{Exame citológico}

Embora a biópsia óssea para realização do exame histopatológico permaneça como padrão de diagnóstico de OSA em cães, a citologia aspirativa com agulha fina (CAAF) pode sugerir o diagnóstico definitivo como meio menos invasivo e de baixo custo (DALECK et al., 2008). Quando o diagnóstico citológico de OSA é inconclusivo, recomenda-se a confirmação por exame histopatológico (SILVEIRA et al., 2008).

$\mathrm{Na}$ CAAF, são observadas células que se caracterizam em ovais ou circulares, com bordas citoplasmáticas distintas, com citoplasma azul brilhante granular e núcleos excêntricos com ou sem nucléolos. Apesar disso, é muito difícil identificar o tipo exato de sarcoma baseado somente na citologia (ALCÂNTARA et al., 2010).

Os aspirados de cães com OSA na maioria das vezes demonstram grande quantidade de células mesenquimais imaturas que podem ter osteóide intracitoplasmático ou extracelular. Em associação aos osteoblastos malignos, osteoblastos benignos e osteoclastos também podem se encontrar presentes. Aspiração por agulha fina de lesões ósseas líticas pode ajudar a excluir osteomielite fúngica ou bacteriana, onde células inflamatórias ou organismos podem ser visualizados (DALECK et al., 2008; SILVEIRA et al., 2008). Uma biópsia de tecido também pode ser usada para diagnóstico citológico preliminar, obtendo-se uma impressão sobre lâmina (OLIVEIRA \& SILVEIRA, 2008a). 
Um estudo realizado por KUMAR et al. (1993) correlacionaram as características clínicas e radiológicas de neoplasias ósseas primárias malignas, com citopatologia e histopatologia em 74 casos humanos, e constataram que, entre essas neoplasias, 38\% foram confirmadas de OSA. Após foi realizada a CAAF em todos os casos, sendo confirmados $94,1 \%$. Havendo correlação de $89 \%$ entre o diagnóstico radiológico e citológico (DALECK et al., 2008).

\section{Biópsia óssea}

O diagnóstico definitivo de uma neoplasia óssea maligna pode ser sugerida pelos sinais clínicos, pelo histórico, pelo exame físico e pelas alterações radiográficas. Entretanto, o diagnóstico definitivo de OSA requer biópsia do tecido tumoral e correta interpretação dos achados histopatológicos (DALECK et al., 2008). A biópsia de tecido ósseo é muito importante para o diagnóstico e tratamento de neoplasias ósseas em cães e gatos (WATERS, 1998).

A biópsia pode ser aberta ou fechada (DALECK et al., 2008). A biópsia aberta é realizada através de incisão de pele, permitindo a obtenção de quantidade ideal de tecido e maior precisão do resultado. Essa técnica necessita de um procedimento cirúrgico com anestesia geral, sendo que na maioria das vezes os pacientes apresentaram inchaço crescente e claudicação do membro, após o procedimento. Os riscos associados à biópsia óssea aberta, em cães com OSA, geralmente, incluem infecção, diagnóstico não conclusivo e fratura iatrogênica (OLIVEIRA \& SILVEIRA, 2008a).

Duas técnicas de biópsia fechada receberam grande atenção: biópsia com o trépano de Michele e com a agulha de Jamshidi (WATERS, 1998). A biópsia fechada é um procedimento com alta precisão diagnóstica $(93,8 \%)$, embora consiga a obtenção de uma pequena quantidade de material, se comparada com a biópsia aberta, as complicações pós-operatórias são amenizadas, oferecendo maior comodidade ao animal (OLIVEIRA \& SILVEIRA, 2008a).

As vantagens das brocas de Michele é poder conseguir uma amostra maior de tecido ósseo, entretanto, pode aumentar o risco de fratura através do local da biópsia. Já as agulhas de Jamshidi obtêm uma amostra menor, diminuindo o risco de fratura patológica após biópsia. Podem ser obtidos diagnósticos precisos em ambas às técnicas em mais de $80 \%$ dos casos (JOHNSON \& HULSE, 2005).

A presença de osteóide é base para o diagnóstico histológico, diferenciando o OSA das demais neoplasias ósseas malignas não osteogênicas, como condrossarcoma e o fibrossarcoma. O diagnóstico de OSA constitui na identificação de osteoblastos malignos (DALECK et al., 2008).

Os osteossarcomas podem ser classificados de acordo com o tipo celular encontrado no exame histológico, podendo ser: pobremente diferenciado, osteoblástico, condroblástico, fibroblástico, telangectásico e tipo células gigantes (Quadro 2). A definição do padrão histológico é dada pelo tipo de matriz e pelas células com maior predominância no tumor (SANTOS, 2009). 
QUADRO 2 - Características histológicas observadas nos subtipos do osteossarcoma da forma central.

\begin{tabular}{ll} 
SUBTIPOS & CARACTERÍSTICAS HISTOLÓGICAS \\
\hline Osteoblástico & $\begin{array}{l}\text { Constituído por osteoblastos anaplásicos, volumosos e células } \\
\text { fusiformes com citoplasma basofílico, núcleos hipercromáticos e } \\
\text { excêntricos. De acordo com as variações na quantidade de } \\
\text { osteóide são subclassificados em: produtivos, com células } \\
\text { tumorais com quantidade abundante de matriz osteóide tumoral } \\
\text { dispostas em trabéculas conferindo um padrão entrelaçado com } \\
\text { células neoplásicas; pouco produtivos, com lesões ósseas líticas } \\
\text { e discreta quantidade de osteóide tumoral em permeio às células } \\
\text { osteoblásticas atípicas com o padrão acima descrito. }\end{array}$ \\
Condroblástico & $\begin{array}{l}\text { Possui células tumorais mesenquimatosas e produz matriz } \\
\text { condróide em abundância, além de osteóide tumoral, dispostas }\end{array}$ \\
Fibroblástico & $\begin{array}{l}\text { lado-a-lado ou entremeando-se. } \\
\text { medida que a lesão evolui, extensas áreas de matriz osteóide }\end{array}$ \\
envolvendo aglomerados de células tumorais. \\
Do tipo células & $\begin{array}{l}\text { Exibe escassa produção de matriz óssea e predomínio de } \\
\text { grandes áreas contendo inúmeras células gigantes } \\
\text { multinucleadas tumorais e presença de osteóide. }\end{array}$ \\
Telangectásio & $\begin{array}{l}\text { Caracterizado pela presença de canais vasculares de diâmetros } \\
\text { variados, revestidos por células e reduzida quantidade de } \\
\text { osteóide. }\end{array}$ \\
\hline Pobremente & $\begin{array}{l}\text { Apresenta quantidade mínima de osteóide típico, ausência de } \\
\text { espículas ou trabéculas de osso tumoral, células neoplásicas } \\
\text { diferenciado } \\
\text { volumosas e pleomórficas ou pequenas, semelhantes às células } \\
\text { reticulares do estroma da medula óssea. }\end{array}$ \\
\hline
\end{tabular}

Fonte: Adaptação de PIMENTA et al., 2013.

\section{Cintilografia óssea}

A cintilografia óssea (CO), além de ser eficaz no diagnóstico, pode ser útil no estadiamento de cães com OSA. O uso da cintilografia óssea tem ajudado a diagnosticar mais rápido a presença de metástases em cães com OSA, entretanto, não é um método diagnóstico valioso para distinguir entre vários tipos de tumores primários. Portanto é uma técnica de elevada sensibilidade para detecção de lesões esqueléticas, porém não é específica para identificação de sítios ósseos tumorais, ou seja, qualquer região com atividade osteoblástica será identificada pela $\mathrm{CO}$, incluindo osteoartrite e infecção (DALECK et al., 2008; OLIVEIRA \& SILVEIRA, 2008a; SILVA, 2009).

Na medicina veterinária, especialmente no Brasil, devido a seu alto custo, tem sido pouca empregada. O exame cintilográfico de animais com neoplasias ósseas, mediante o uso de metileno difosfato marcado com tecnécio 99m (99mTcMDP), é mais eficaz que o exame radiográfico, principalmente, na detecção de metástases (DALECK et al., 2008).

O radiofármaco 99mTcMDP é administrado por via intravenosa, incorpora-se aos sítios de neoformações ósseas e áreas de remodelamento ou a uma região de aumento de fluxo sanguíneo. Utiliza-se uma câmara gama que registra a radioatividade entre os sítios do osso, o que pode ser mostrado como imagem. A 
detecção do radionuclídeo no osso pela câmara é indicativa de atividade metabólica esquelética, complementando a informação estrutural das radiografias (DALECK et al., 2002).

\section{Tomografia computadorizada e ressonância magnética}

A tomografia computadorizada (TC) e a ressonância magnética (RM) permitem diagnóstico mais precoce das lesões metastática (SILVA, 2009). TC ou a RM podem fornecer informações essenciais para se estabelecer um planejamento cirúrgico, por proporcionarem visualização desejada da extensão de tecidos moles envolvidos (OLIVEIRA \& SILVEIRA, 2008a).

$\mathrm{Na}$ atualidade a TC é uma opção fundamental para detecção, estadiamento e acompanhamento das neoplasias. Esse tipo de investigação, com alta sensibilidade e especificidade, possibilita a avaliação de vários órgãos com um único exame. A avaliação por TC proporciona uma imagem tridimensional obtida seção por seção em planos transversal, dorsal, sagital e oblíquo. Possui vantagem sobre a radiografia convencional por apresentar grande sensibilidade para diferenciar pequenas atenuações dos raios $X$ e ser isenta de sobreposições de estruturas (RODASKI \& PIEKARZ, 2008).

Os exames com ressonância magnética, da mesma maneira que a tomografia computadorizada, produzem imagens transversais em diversos planos mostrando forma, tamanho e localização da neoplasia. Ao contrário da radiografia e da tomografia computadorizada a ressonância magnética usa campos magnéticos e radiofrequência, fornecendo imagens sem a necessidade da radiação (RODASKI \& PIEKARZ, 2008). A RM proporciona maior precisão estimada do tumor, sendo reconhecida como a melhor modalidade para avaliação pré-operatória de OSA apendicular, principalmente, na cirurgia de preservação do membro (DALECK et al., 2008; OLIVEIRA \& SILVEIRA, 2008a).

\section{Tratamento}

Uma vez confirmado osteossarcoma, existem várias opções de tratamento, definitivas ou paliativas, que podem ser oferecidas ao proprietário. Se nenhumas das alternativas de tratamento forem aceitas, existem algumas alternativas para pelo menos proporcionar o controle da dor na tentativa de oferecer boa qualidade de vida (OLIVEIRA \& SILVEIRA, 2008a; SILVA, 2009). Segundo WATERS (1998), a cirurgia é a terapêutica mais importante no tratamento das neoplasias ósseas.

Uma decisão terapêutica segura deve estar aliada aos resultados dos exames clínico e físico, hematológico, bioquímico, dentre outros, podendo uma doença subjacente ao OSA proporcionar um prognóstico ruim ou alteração do tratamento (OLIVEIRA \& SILVEIRA, 2008a).

\section{Amputação do membro}

O primeiro tratamento para OSA apendicular em cães foi a amputação do membro afetado, entretanto, deve ser considerada apenas como tratamento paliativo, se for realizada isoladamente. (OLIVEIRA \& SILVEIRA, 2008a; SILVA, 2009). A principal vantagem da amputação do membro afetado é que o procedimento possibilita a ressecção completa do tumor primário e, 
consequentemente, o alívio da dor (OLIVEIRA \& SILVEIRA, 2008a ; ANDRADE, 2009).

A intervenção cirúrgica, associada à quimioterapia, consiste na terapêutica que possibilita maior sobrevida, sendo indicada com maior frequência para o tratamento de osteossarcoma apendicular (OLIVEIRA \& SILVEIRA, 2008a; SILVEIRA et al., 2008), proporcionando em média de 300 a 400 dias de vida ao animal (JOHNSON \& HULSE, 2005). Quando realizada sem associação com a quimioterapia, o tempo de sobrevivência é bem curto, aproximadamente de três a seis meses de vida (DALECK et al., 2008).

Após a amputação, $70 \%$ a $90 \%$ dos cães desenvolvem metástase pulmonar em até um ano de cirurgia, sendo que $85 \%$ dos cães morrem de doença metastática com sobrevivência em média de seis meses. Os 15\% restantes são considerados "curados" (OLIVEIRA \& SILVEIRA, 2008a).

Para os tumores localizados nos membros torácicos existem duas técnicas: amputação do membro com remoção da escápula ou amputação do membro pela desarticulação escapuloumeral. Em ambas as técnicas, deve ser feita infiltração de lidocaína no plexo braquial, para proporcionar maior conforto no pós-cirúrgico. Quando o OSA acomete os membros pélvicos, a amputação por desarticulação da articulação coxofemoral é a mais utilizada (JOHNSON \& HULSE, 2005; DALECK et al., 2008; SILVA, 2009).

A elevada taxa de metástases contribui para um prognóstico desfavorável, estabelecendo a necessidade de avaliar o uso de quimioterapia adjuvante ao tratamento após a amputação. Os animais com OSA apendicular têm sido tratados atualmente em nosso país com amputação do membro e terapia adjuvante (quimioterapia ou imunoterapia) (OLIVEIRA \& SILVEIRA, 2008a).

Uma grande quantidade de proprietários se recusa a autorizar a amputação do membro afetado, impossibilitando que o profissional realize a terapia mais indicada, o que pode reduzir as chances de proporcionar maior sobrevida para 0 paciente (OLIVEIRA \& SILVEIRA, 2008a; SILVA, 2009).

\section{Quimioterapia}

A quimioterapia é indicada como adjuvante no tratamento cirúrgico da neoplasia primária para tentar prevenir ou atrasar o início de metástases (ANDRADE, 2009). O uso de quimioterápicos altera o comportamento natural das células neoplásicas, reduzindo a incidência de metástases pulmonares e ósseas. É imprescindível a resposta individual dos cães à quimioterapia, podendo resultar em insucesso. Entretanto, é necessária a administração de um fármaco citotóxico, principalmente nos casos de OSA, devido ao alto poder metastático, para diminuir a carga total do tumor, aumentar o intervalo livre de doença e melhorar a qualidade de vida do animal, fornecendo alívio dos sintomas associados à neoplasia (DALECK et al., 2008; OLIVEIRA \& SILVEIRA, 2008a).

A cisplatina é empregada no tratamento de OSA apendicular em cães, reduzindo a ocorrência de metástases pulmonares. Entre os agentes quimioterápicos, a cisplatina parece ser a que mais aumenta o tempo de sobrevivência destes pacientes (SILVEIRA et al., 2008).

A cisplatina é o fármaco citotóxico mais nefrotóxico usado no tratamento de neoplasias em cães. Cerca de 80 a 90\% dela é eliminada na urina, sendo filtrada livremente pelo glomérulo devido seu baixo peso molecular. A nefrotoxicidade é seu maior efeito colateral e está correlacionada com a dose. A dose recomendada é de 
60 a $70 \mathrm{mg} / \mathrm{m}^{2}$, com intervalos de 21 dias, sendo necessário um total de três a seis sessões. Algumas medidas podem ser úteis para minimizar a nefrotoxicidade desse fármaco, incluindo doses menores, administração de fluidos antes e após a quimioterapia e o uso de diuréticos osmóticos. A êmese também tem sido uma grande preocupação quando se utiliza a cisplatina, devendo ser utilizados antieméticos para reduzir esse efeito colateral, entre eles a ondansetrona, na dose de $0,4 \mathrm{mg} / \mathrm{kg}$ (DALECK et al., 2008).

Recomenda-se, se estiver utilizando a cisplatina, fazer avaliação da função renal do paciente, antes de estabelecer o tratamento, e analisar os parâmetros hematológicos e renais, antes de cada sessão de quimioterapia (DALECK et al., 2002). Segundo DALECK et al. (2008), a carboplatina é outro quimioterápico indicado como terapia adjuvante do OSA. A dose recomendada para cães é de $300 \mathrm{mg} / \mathrm{m}^{2}$ (IV) e para gatos $150 \mathrm{mg} / \mathrm{m}^{2}$ (IV), repetida a cada 21 dias, num total de quatro sessões. Não tem os efeitos nefrotóxicos da cisplatina, no entanto, é importante induzir a diurese.

A poliquimioterapia tem demonstrado bons resultados. Uma boa combinação para o OSA é a cisplatina com a doxorrubicina. A dose da cisplatina é $60 \mathrm{mg} / \mathrm{m}^{2}$ e da doxorrubicina é de $30 \mathrm{mg} / \mathrm{m}^{2}$, ambas por via IV. Deve-se levar em consideração a diurese, assim como a administração de antieméticos. Fazer o monitoramento do paciente antes e após a realização de cada ciclo, através de provas bioquímicas, auscultação cardíaca, eletrocardiograma e ecocardiografia (DALECK, et al., 2008).

Outro protocolo que pode ser realizado é a associação da carboplatina na dose de $300 \mathrm{mg} / \mathrm{m}^{2}$ com a doxorrubicina na dose de $30 \mathrm{mg} / \mathrm{m}^{2}$, ambas por via IV. O tratamento com essas medicações requer monitoração cardíaca e renal, além do controle das células sanguíneas (DALECK et al., 2008).

\section{Radioterapia}

A radioterapia é um método muito útil para o tratamento de osteossarcomas apendiculares e axiais, também utilizada para outros tipos de neoplasias (SILVA, 2009). Pode proporcionar o alívio ou a remissão da dor por longos períodos e o retardo no crescimento neoplásico, sendo o procedimento indicado quando há impossibilidade de excisão cirúrgica tumoral (OLIVEIRA \& SILVEIRA, 2008a SILVA, 2009).

Apesar de existir casos de osteossarcoma induzido por radiação em animais, a associação da radioterapia com a cirurgia pode prolongar o tempo de sobrevida do animal (SILVA, 2009), podendo, às vezes, ser curativa (OLIVEIRA \& SILVEIRA, 2008; ANDRADE, 2009).

\section{Preservação do membro}

A técnica de preservação do membro está indicada para cães com tumores ósseos apresentando distúrbios ortopédicos (displasia) ou neurológicos, que não deambularão adequadamente após a amputação, ou ainda, naqueles casos em que os proprietários rejeitem a amputação do membro. Os candidatos para o salvamento do membro são animais com osteossarcoma confirmado clinicamente, cujo tumor afeta menos que $50 \%$ do osso ao exame radiográfico e livre de metástase (DALECK et al., 2009; JOHNSON \& HULSE, 2005; OLIVEIRA \& SILVEIRA, 2008a; SILVA, 2009). Um pré-requisito para realizar a cirurgia de preservação do membro é o 
banco de aloenxertos ósseos corticais congelados e esterilizados (DALECK et al., 2002).

A cirurgia de preservação do membro, denominada "Limb-sparing", envolve a remoção do tumor e a reconstrução da coluna óssea, com ou sem artrodese da articulação adjacente (SILVA, 2009). Essa técnica consiste na exérese do segmento ósseo afetado com a neoplasia, com margem de segurança de $2 \mathrm{~cm}$, no defeito ósseo implanta-se uma prótese óssea fixada com placa metálica e parafusos aos ossos circunvizinhos (RIBEIRO et al., 2011).

Os cães também são tratados com cisplatina intravenosa e, em geral, mantêm quase toda a função normal do membro. Os tempos de sobrevida com esta técnica são compatíveis com aqueles obtidos com a amputação associada à cisplatina, com a vantagem adicional aos proprietários de possuírem um animal com os quatro membros (SILVA, 2007).

Essa técnica tem sido descrita em cães com osteossarcoma, para as seguintes regiões: distal do rádio, proximal do úmero, distal da tíbia e proximal do fêmur, mas a técnica para tumores distais do rádio tem apresentado resultados mais favoráveis (DALECK et al., 2008; SILVA, 2009). A preservação em regiões umerais proximais não tem obtido sucesso considerável (JOHNSON \& HULSE, 2005) e, cães com neoplasias localizadas na porção distal do fêmur ou da tíbia não devem ser submetidos à cirurgia de salvamento do membro devido a elevada taxa de infecção decorrente da escassez de recobrimento muscular nessas regiões. Os tumores localizados na tíbia proximal ou fêmur distal representam problemas pela impossibilidade de preservar a articulação do joelho, portanto, a função insatisfatória e as taxas de complicação desencorajam a indicação da técnica nestas áreas. Visto que os tumores ósseos primários ocorrem em locais metafisários, a articulação vizinha deverá ser submetida à artrodese após a remoção do tumor (DALECK, et al., 2008; SILVA, 2009).

Os cuidados após a técnica de salvamento do membro incluem (JOHNSON \& HULSE, 2005):

- sistema de drenagem por sucção fechado e a remoção do dreno quando a drenagem diminuir, geralmente um dia após a cirurgia;

- o membro deve ser envolvido por atadura acolchoada para controlar o inchaço pós-operatório;

- a incisão deve ser protegida com ataduras e/ou colar elizabetano para evitar que o animal se automutile;

- o exercício deve ser diminuído por 3 a 4 semanas, entretanto, o exercício controlado ou a fisioterapia podem ser necessários para evitar que haja contratura de flexura dos dedos.

\section{Prognóstico}

O prognóstico no caso de OSA é sempre de reservado a desfavorável, tendo em vista o curso fatal da doença e a sobrevida, que costuma ser curta, mesmo se for realizado algum protocolo terapêutico. Em média $90 \%$ dos casos, a doença micrometastática está presente na hora da apresentação ou diagnóstico da neoplasia óssea primária e independentemente do método de tratamento, praticamente todos os pacientes serão eutanasiados devido à doença metastática e/ou recidiva local do tumor (SANTOS, 2009). O prognóstico para o OSA extraesquelético em cães também é desfavorável, tendo em média dois meses de vida (ARAÚJO et al., 2006). 
A média de sobrevivência dos animais acometidos pelo osteossarcoma apendicular é pouco variável de acordo com a literatura, porém percebe-se que os autores dos trabalhos pesquisados são unânimes quando descrevem que a sobrevida aumenta quando se associa cirurgia com quimioterapia adjuvante (SANTOS, 2009).

\section{CONSIDERAÇÕES FINAIS}

Cães de grande porte e gigantes, de meia idade a idosos são predispostos a desenvolver o osteossarcoma, sendo os ossos apendiculares os mais acometidos. Existe uma maior incidência de osteossarcoma acometendo os membros torácicos quando comparada com os membros pélvicos. Radiografias torácicas raramente demostram a presença de metástases pulmonares no momento da consulta. Intervenção cirúrgica associada à quimioterapia é o tratamento que proporciona maior sobrevida para o paciente.

Por se tratar de tumor extremamente agressivo é importante o diagnóstico precoce e estando confirmada a malignidade do tumor, a terapêutica deve ser iniciada imediatamente. Vale ressaltar que em grau avançado da neoplasia não haverá resposta positiva do tratamento.

\section{REFERÊNCIAS}

ALCÂNTARA, D.; REZENDE, L.C.; MILIGNO, M.A.; MARIA, D.A. Osteossarcoma canino. Enciclopédia Biosfera, Centro Científico Conhecer - Goiânia, v.6, n.10, p. 16, 2010. Disponível em: http://www.conhecer.org.br Acesso em: 10/10/2014.

ANDRADE, S.A.F. Tumores Ósseos em cães. Revista UNILUS Ensino e Pesquisa. v. 5, n. 9, p. 5-12, jul./dez. 2008. Disponível em: http://revista.lusiada.br Acesso em: 02/10/2014.

ANDRADE, S. A. F. Osteossarcoma canino. Revista UNILUS Ensino e Pesquisa. v. 6, n. 10, p. 5-12, jan./jun. 2009. Disponível em: http://revista.lusiada.br Acesso em: 15/10/2014.

ARAÚJO A.C.P.; GAIGA L.H.; SEITZ A.L.; DREIMEIER, D. Osteossarcoma extraesquelético primário testicular em cão criptorquida. Acta Scientiae Veterinariae. Universidade federal do Rio Grande do Sul, Porto Alegre, Rio Grande do Sul, v.34, n. 2, p.197-200, julho de 2006. Disponível em: http://www.redalyc.org Acesso em: 16/10/2014.

CANOLA, J.C.; MEDEIROS, F.P. Radiografia Convencional e Ultra-sonografia no Diagnóstico de Neoplasias. In: DALECK, C. R.; DE NARDI, A. B.; RODASKI, S. (Ed.) Oncologia em Cães e Gatos. São Paulo: Roca, 2008, cap. 27, p. 93-120.

COUTO, G.C. Oncologia. In: NELSON, W. R.; COUTO, G. C. (Ed.) Medicina Interna de Pequenos Animais. 3. ed. Rio de Janeiro: Elsevier, 2006. p. 1059-1117.

DALECK, C.R.; CANOLA, J.C.; STEFANES, S.A.; SCHOCKEN, P.F.L.; DE NARDI, A.B. Estudo retrospectivo de osteosarcoma primário dos ossos da pelve em cães em 
um período de 14 meses. Brazilian Journal of veterinary Research and Animal Science, São Paulo, v. 43, n. 1, p. 125-131, 2006. Disponível em: http://www.revistas.usp.br Acesso em: 05/10/2014.

DALECK, C. R.; FONSECA, C. S.; CANOLA, J. C. Osteossarcoma canino - revisão. Revista de Educação Continuada em Medicina Veterinária e Zootecnia. São Paulo, v. 5, n. 3, p. 233-242, 2002. Disponível em: http://revistas.bvs-vet.org.br Acesso em: 17/10/14.

DALECK, C.R.; REPETTI, C.S.F.; MARTINS, M.R.; DE NARDI, A.B.; Neoplasias Ósseas. In: DALECK, C. R.; DE NARDI, A. B.; RODASKI, S. (Ed.) Oncologia em Cães e Gatos. São Paulo: Roca, 2008, cap. 27, p. 399-410.

JOHNSON, A.L.; HULSE, D.A. Neoplasias Ósseas. In: FOSSUM, T. W (Ed). Cirurgia de pequenos animais. 2. ed. São Paulo: Roca, 2005. p. 1165-1176.

KUMAR, R. V.; RAO, C. R.; HAZARIKA, D. et al. Aspiration biopsy cytology of primary bone lesions. Acta Cytology, v. 37, n.1, p. 83-89, 1993.

MARTELLI, A.; TEIXEIRA, L.B.C.; SANTOS JR, A. R. Aspectos histopatológicos e histoquímico de osteossarcomas em cães. Estudos de Biologia, v.29, a. 67, p. 179189, abr/jun, 2007. Disponível em: http://www2.pucpr.br/ Acesso em: 17/10/2014.

MORRIS, J.; DOBSON, J. Oncologia em Pequenos Animais. São Paulo: Roca, 2007. p. 312.

OLIVEIRA, F.; SILVEIRA, P.R. da. Osteossarcoma em cães. Revista Científica Eletrônica de Medicina Veterinária, a. 6, n.10, p. 1-21, Janeiro de 2008a Periódicos Semestral. Disponível em: http://faef.revista.inf.br Acesso em: 03/10/14.

OLIVEIRA, F.; SILVEIRA, P.R. da. Osteossarcoma em cães (revisão de literatura). Revista Científica Eletrônica de Medicina Veterinária, a. 6, n.11, p. 1-7, Julho de 2008b - Periódicos Semestral. Disponível em: http://faef.revista.inf.br Acesso em: 04/10/14.

PAZZINI, J.M.; DALECK, C.R. Oncologia - Osteossarcoma. In: ROZA, M.; OLIVEIRA, A.L. A.; DE NARDI, A. B.; SILVA, R. L. Dia-a-dia Tópicos Selecionados em Especialidades Veterinárias. Curitiba: Medvep, 2013. p.

PIMENTA, V.S.C.; BRAGA, K. M.S.; MACHADO, P.A.; PRADO, Y.C.L.; ARAÚJO, E. G. Osteossarcoma Canino e Humano: Uma visão comparada. Enciclopédia Biosfera, Centro Científico Conhecer - Goiânia, v.9, n.17, p. 1971- 1991, 2013. Disponível em: http://www.conhecer.org.br Acesso em: 09/10/2014.

RIBEIRO, F.P.; FRIOLANI, M.; CABRINI, T.M.; DIAS, L.G.G.G. Osteossarcoma em esqueleto axial em cão - Relato de caso. Revista Científica Eletrônica de Medicina Veterinária, a. 9, n.17, Julho de 2011 - Periódicos Semestral. Disponível em: http://faef.revista.inf.br Acesso em: 09/10/14. 
RODASKI, S.; PIEKARZ, C.H. Diagnóstico e Estadiamento Clínico. In: DALECK, C. R.; DE NARDI, A.B.; RODASKI, S. (Ed.) Oncologia em Cães e Gatos. São Paulo: Roca, 2008 , cap. 27 , p. 51-74.

SANTOS, S.O. Osteossarcoma canino: Relato de casos. 2009. 59 f. Monografia (Especialização Latu senso em clínica médica e cirúrgica em pequenos animais), Universidade Castelo Branco, Rio de Janeiro, 2009.

SILVA, D.K. Preservação do membro em cães com osteossarcoma apendicular. 2009. 45f. Monografia (Graduação em Medicina Veterinária), Universidade Federal do Rio Grande do Sul, Porto Alegre, 2009.

SILVA, V.F. Osteossarcoma em Cães Revisão de Literatura. 2007. 36 f. Monografia (Especialização Latu senso em clínica médica e cirúrgica em pequenos animais), Universidade Castelo Branco, Rio de Janeiro, 2007.

SILVEIRA, P.R.; DALECK, C.R.; EURIDES, D.; SILVA, A.F.; REPETTI, C.S.F.; DE NARDI, A.B. Estudo retrospectivo de osteossarcoma apendicular em cães. Ciência Animal Brasileira, v. 9, n. 2, p. 487-495, abr.jun. 2008. Disponível em: http://www.revistas.ufg.br Acesso em: 02/10/14.

WATERS, D.J. Oncologia - Sistema Músculo Esquelético. In: SLATTER, D. (Ed.) Manual de Cirurgia de Pequenos Animais. 2. ed. São Paulo: Manole, 1998. p. 2607-2624. 